\title{
A Study on Learning Motivation and Ayurvedic Personality Types of Caregiver Trainees
}

\author{
Mee-Sook Cheong1), Jae-Gyeong Lee2)
}

\begin{abstract}
This study analyzes the relationship between learning motivation and personality type of caregiver trainees using a learning motivation questionnaire based on the Ayurvedic personality type. The subjects of this study are selected caregiver trainees, and their motivation for learning was employment and family support (64.1\%). The proportion of males and females in the sample was high due to caregiver's work $(90.6 \%$ of females). In the relationship between learning motivation and personality type, $53.1 \%$ of trainees were Kapha type. The Kapha type personality is about love, and devotion. This result reflected well the emotional characteristics of parents or dependents. The next was Vata type, which was $28.1 \%$. This is due to the active personality type of the Vata type. In addition, in case of self-development, the Pitta type occupied $72.8 \%$ (8/11 case). The Pitta type is goal-oriented as revealed with the respondents of the study. The learning motivation of caregiver trainees is found to have a significant effect on their personality types. Learning motivation and personality types of caregiver trainees are important factors that affect the quality of care services. Korea has entered an aging society. The caregiver's role and importance are emphasized. The results of this study suggest that the data may be used to motivate the learning of caregiver trainees, and as career standard upon selecting qualified candidates as caregivers.
\end{abstract}

Keywords: Caregiver, Motivation for Learning, Personality Type, Ayurveda, Career Selection

\section{Introduction}

\subsection{Trends}

The Organization for Economic Co-operation and Development (OECD) released the Health Statistics 2018 on July 2, 2019 stating that the life expectancy of Korea is 82.7 years, which is 2.0 years longer than the OECD average. In addition, Korea's life expectancy has increased by

Received(January 03, 2020), Review Result(1st: February 05, 2020, 2nd: March 20, 2020), Accepted(May 27, 2020)

1) (Professor, Corresponding Author) 02838 Dept. Naturopathy, DongBang Culture Univ., Seongbook-dong, Seongbook-gu, Seoul, Korea email: ayurveda16@naver.com

2) (Ph.D. course) 02838 Dept. Naturopathy, DongBang Culture Univ., Seongbook-dong, Seongbook-gu, Seoul, Korea email: ljg4129@naver.com 
1.8 years in the past five years, which is higher than the OECD's 0.9-year increase[1].

The increase in life expectancy is causing the rapid aging of Koreans. The elderly aged 65 and over are expected to be $14.9 \%$ in $2019,20.3 \%$ in 2025 and $46.5 \%$ in 2067 . As a result of aging, $5.6 \%$ of the elderly aged 65 or older received long-term care services. The $2.7 \%$ of the population received facility services lower than the OECD average (3.5\%). However, in-home service supply and demand rose $1.6 \%$ in the last five years from $4.0 \%$ in 2012 . The trend is increasing. Elderly welfare facilities are also increasing every year from 73,774 in 2014 to 77,382 in 2018[2].

The government has systematically operated long-term care facilities since July 2008. It is the long-term care insurance and caregiver system for the aged. Caregivers must complete a prescribed curriculum at a government-approved training institution. They must pass the national exam, which is to obtain a state-certified caregiver certificate. They visit homes primarily for welfare or home services. In addition, it supports physical activity and daily life to those who are unable to live alone at home due to aging or senile disease[3].

The caregiver's job is to specialize in the physical and household activities of the elderly and to collect information about the subject from doctors, nurses, and family members to plan care services. Caregivers also work to maintain the cleanliness of their persons who need care, provide food and medication support, excretion, exercise, emotional support, environmental management. and daily life support. They also take care of the person who needs care services, keeping their posture and providing advices on life support, physical assistance, and coping with difficulties in daily life[4].

Thus, the aging trend in Korea will continue to increase the demand for caregivers. Successful elderly care services require finance and support materials. Health care services are labor-intensive. Considering these characteristics requires the beliefs and values of those involved. Caregiver's qualifications and abilities have a great influence on their performance[5], which means that personal characteristics such as learning motivation, learning ability and personality are considered[6].

\subsection{Motivation for Learning \& Personality Type}

Motivation for learning is the driving force for individuals to learn and perform new knowledge and skills. The learner's personality is different from person to person. Not everyone can have the same response to stimuli coming from outside. The processes that occur inside them differ in their selective perception, cognition and acceptance. and outwardly 
behaviors. We look at language or behavior and subjectively guess their personal patterns[7]. Personality is the subject of all human behavior, including caregivers. Human behavior is determined by personality. In the meantime, efforts have been made to classify human personalities into several types. A study on the personality type of nursing caregivers showed that the higher the personality type with sincerity, affinity, openness, and extroversion, the higher the behavior-oriented strategy, the nature rewarding strategy, and the constructive strategy[8].

The personality is categorized into several types typologically. Personality types are mainly classified based on physical physiology, psychology, and metaphysics. Physical physiology is based on the theory that a person's constitution determines personality, and psychology explains the relationship between temperament and body shape from a psychopathological standpoint. There are also metaphysical theories that separate personality types according to lifestyle.

From the point of view of personality type in terms of body physiology, there is the Sasang constitution and the Ayurveda. Sasang constitution is divided into four types: Tayang, Taeum, Soyang, and Soum. This is the result of Lee Jema's research and has recently been subdivided into eight constitutions. Ayurveda is largely divided into Vata (air), Pitta (fire), and Kapha (water). These two theories have something in common from the point of view that the personality type is born. However, there are certain differences. Sasang constitution is classified into four fixed constitutions, and eight constitutions are classified into eight fixed constitutions. However. In Ayurveda, the three mental types Sattva (harmony), Rajas (activity), and Tamas (inactivity) are added to subdivide the human type further. Ayurveda is the view that all three types are contained in our body, and that the most dominant of the three is the personality type. Therefore, there is a characteristic that all of the individual characteristics are different[9].

Ayurveda means life science in Sanskrit. And this is India's traditional natural healing system and has been handed down from ancient India. Ayurveda's origin dates to $3000 \mathrm{BC}$, and it views human beings as an integrated body, mind, and soul. In Ayurveda, the body is a mental organism and supports the action of the senses. In addition, the body is viewed as a medium of cognition designed to facilitate the experience by the mind. In this regard, Ayurveda can be called a holistic system[10].

The psychological characteristics of the Ayurvedic personality type are as follows.

The Vata type has a mind that tends to change interest and tendency. It is chatty, intelligent, and comprehensible. The Vata type is a talented teacher, computer programmer, and can represent an individual's abilities in communication media. This type is sociable and likes 
to get along well with people. It is the most flexible and adaptable of the three types[11].

The Pitta type is intelligent and clever but can be critical and self-righteous. This type can easily get angry and be insensitive to other people's moods. The Pitta type likes to use energy and power and enjoys debate. Therefore, it is a type often seen in scientists, leaders, soldiers, police, politicians, and lawyers[12].

The Kapha type is emotional in nature and is loving, committed, and loyal.

This type is sentimental and cries easily. They are especially friendly to people they know and are very attached to their families. Therefore, Kapha is a good parent or caregiver, a mother, and a wife. Therefore, based on Ayurvedic personality type, this is the most optimal personality type of caregivers[13].

Caregivers are key personnel in the care of the elderly. Caregiver's learning motivation and personality type are important factors related to the quality of care services for the elderly. The previous studies related to this are as follows. "A Study of the Subjective Quality of Life, and Locus of Control of Caregiver Trainees" (2008, Y. S. Jung); "A Study on the Self leadership Mediating Effect and the Occupational Identity moderating Effect of Caregiver's Personality Type on the Relationship between the Personal Innovation Behavior and Service Quality" (2018. K. O Kim), and; "Effect of Academic Motivation on The Learning Flow with Training for Caregivers" (2011, H. R Noh). However, there was no direct study on the relationship of personality type and learning motivation among nursing home caregiver trainees.

Therefore, this study intends to analyze the learning motivation and personality type of trainees preparing caregivers. The results of this study are expected to improve the quality of nursing caregivers and to be used as basic data for personality type and motivation. The following research questions are selected.

First, what is the learning motivation of caregiver trainees?

Second, what is the distribution of personality types of caregiver trainees?

Third, what kind of correlation is there between learning motivation and personality type of caregiver trainees?

\section{Study Method}

\subsection{Study Target}

This study selected trainees who are being trained at the caregiver training center located in G City. The purpose of this study was explained, and those who agreed with the voluntary 
consent answered the questionnaire.

\subsection{Study Design}

This study identifies the relationship between the learning motivation of the caregiver trainee and their Ayurvedic personality type through character type analysis.

The study used the data from the survey conducted from October 2019 to mid-February 2020. A total of 72 questionnaires were distributed and 67 were collected, with a $93 \%$ recall rate. Among these, 64 copies were used for the study, excluding three poor-response questionnaires.

\subsection{Study Tool}

The questionnaire consists of demographic factors, items on learning motivation of the caregiver towards his study, and questions based on Ayurveda personality. This questionnaire type was used by Hwang Soon-deok (2019)[14]. The survey consists of 45 questions on personality types and motivation for learning, and 6 questions on general items, a total of 51 items. The coefficient of confidence (Cronbach' alpha) of the Ayurveda type test used in this study is 0.761 , as the reliability test standard.

\subsection{Data Analysis}

The data collected for this study were analyzed statistically according to the characteristics and purpose of the measurement variables using SPSS (Statistical Package for the Social Science) WIN 21.0 Program. The analysis method used frequency analysis to determine the demographic composition of the respondents. Correlation and cross-analysis were conducted to verify the hypothesis.

\section{Results}

\subsection{General Characteristic}

The general characteristics of those surveyed in this study are shown in Table 1. According to the gender distribution of the study, 58 respondents (90.6 percent) are women, far higher than men. Based on age, 9 people who answered are under 40s (14.1\%), 34 people in 50s (53.1\%), 
19 people in $60 \mathrm{~s}(29.7 \%)$, and 2 people $(3.1 \%)$ in 70 s or older were in their 50 s. The average age was 56.7 years old. Accounting for the largest portion of the respondents are 44 housewives (68.8\%), 12 working in other jobs (18.8\%), and 8 looking for jobs (12.4\%). The rate of disease such as high blood pressure and diabetes, which are chronic disease, stood at 51.5 percent.

[Table 1] General Characteristics of the Study Subjects

\begin{tabular}{|c|c|c|c|}
\hline Categories & Classification & Frequency(n) & Share $(\%)$ \\
\hline \multirow{2}{*}{ Sex } & Male & 6 & 9.4 \\
\hline & Female & 58 & 90.6 \\
\hline \multirow{4}{*}{ Age } & under forty & 9 & 14.1 \\
\hline & $50 \mathrm{~s}$ & 34 & 53.1 \\
\hline & $60 \mathrm{~s}$ & 19 & 29.7 \\
\hline & 70s and older & 2 & 3.1 \\
\hline \multirow{3}{*}{ Current Job } & housewife & 44 & 68.8 \\
\hline & other jobs & 12 & 18.8 \\
\hline & inoccupation & 8 & 12.4 \\
\hline \multirow[t]{2}{*}{ Disease presence } & $\begin{array}{c}\text { Chronic disease } \\
\text { (Hypertension / diabetes) }\end{array}$ & 33 & 51.5 \\
\hline & No disease & 31 & 48.5 \\
\hline
\end{tabular}

\subsection{Learning Motivation and Personality Type}

The learning motivation of the study subjects was highest for 24 (37.5\%) jobs, followed by 17 (26.6\%) motivations to support the family. In addition, 12 self-developed (18.8\%) and 11 motivated to prepare for old age (17.2\%). The purpose of employment and family support was $64.1 \%$.

[Table 2] Analysis of Learning Motivation of Subjects

\begin{tabular}{c|c|c|c|c|c}
\hline \multicolumn{2}{c|}{} & Frequency(n) & Share(\%) & Effective share(\%) & Cumulative share(\%) \\
\hline \multirow{4}{*}{$\begin{array}{c}\text { Study } \\
\text { motivation }\end{array}$} & For Job & 24 & 37.5 & 37.5 & 37.5 \\
\cline { 2 - 6 } & Support for family & 17 & 26.6 & 26.6 & 64.1 \\
\cline { 2 - 6 } & Prepare for old age & 12 & 18.8 & 18.8 & 82.9 \\
\cline { 2 - 6 } & Self-development & 11 & 17.2 & 17.2 & 100.0 \\
\cline { 2 - 6 } & Total & 64 & 100.0 & 100.0 & \\
\hline
\end{tabular}

Based on personality types of the study subjects, 34 (53.1\%) of the respondents are likely Kapha, 18 are Vata (28.1\%), and 12 are Pitta (18.8\%). 
[Table 3] Analysis of Ayurvedic Personality Types of Subjects

\begin{tabular}{c|c|c|c|c|c}
\hline \multicolumn{2}{l|}{} & Frequency(n) & Share $(\%)$ & Effective share $(\%)$ & Cumulative share(\%) \\
\hline \multirow{4}{*}{$\begin{array}{c}\text { Ayurvedic } \\
\text { Personality Types }\end{array}$} & Vata & 18 & 28.1 & 28.1 & 28.1 \\
\cline { 2 - 6 } & Pitta & 12 & 18.8 & 18.8 & 46.9 \\
\cline { 2 - 6 } & Kapha & 34 & 53.1 & 53.1 & 100.0 \\
\cline { 2 - 6 } & Total & 64 & 100.0 & 100.0 & \\
\hline
\end{tabular}

\subsection{Correlation between Learning Motivation and Personality Type}

[Table 4] shows the results of cross-analysis of the correlation between study motivation and personality type.

[Table 4] General Characteristics of the Subject Ayurveda Personality Type

\begin{tabular}{|c|c|c|c|c|c|c|}
\hline \multirow{2}{*}{\multicolumn{3}{|c|}{ Ayurvedic Personality Type }} & \multicolumn{3}{|c|}{ Type } & \multirow{2}{*}{ Total } \\
\hline & & & Vata & Pitta & Kapha & \\
\hline \multirow{8}{*}{$\begin{array}{c}\text { Study } \\
\text { motivation }\end{array}$} & \multirow{2}{*}{ For Job } & Frequency & 3 & 1 & 20 & 24 \\
\hline & & Expected frequency & 6.8 & 4.5 & 12.8 & 24.0 \\
\hline & \multirow{2}{*}{ Support for family } & Frequency & 6 & 1 & 10 & 17 \\
\hline & & Expected frequency & 4.8 & 3.2 & 9.0 & 17.0 \\
\hline & \multirow{2}{*}{ Prepare for old age } & Frequency & 8 & 2 & 2 & 12 \\
\hline & & Expected frequency & 3.4 & 2.3 & 6.4 & 12.0 \\
\hline & \multirow{2}{*}{ Self-development } & Frequency & 1 & 8 & 2 & 11 \\
\hline & & Expected frequency & 3.1 & 2.1 & 5.8 & 11.0 \\
\hline & \multirow{2}{*}{ Total } & Frequency & 18 & 12 & 34 & 64 \\
\hline & & Expected frequency & 18.0 & 12.0 & 34.0 & 64.0 \\
\hline
\end{tabular}

[Table 5] General Characteristics of the Subject Ayurveda Personality Type Chi-square Test

\begin{tabular}{c|c|c|c}
\hline Chi-square test & Value & Degrees of freedom & $\begin{array}{c}\text { Probability of approximate } \\
\text { Significance (Two-sided test) }\end{array}$ \\
\hline Pearson Chi-square & $41.250 \mathrm{a}$ & 6 & .000 \\
\hline Likelihood-ratio & 36.420 & 6 & .000 \\
\hline Linear to linear combination & 9.241 & 1 & .002 \\
\hline Effective cases & 64 & & \\
\hline
\end{tabular}

The result of this analysis showed that the Pearson correlation test value between the learning motivation and personality type of the caregiver trainees-respondents is 41.250, with 6 degrees of freedom. Therefore, the significance probability is .000 , which shows statistically significant results at the level of .05 .

\section{Conclusion}

This study was conducted among caregiver trainees in caregiving. It analyzed the learning motivation and the Ayurvedic personality type of the respondents to understand the 
relationship between these two variables. The study used the data answered by 67 respondents in a caregiver institution in G City.

The results obtained through this study are as follows. First, due to the nature of the work of caregivers, the proportion of female subjects is greater than the male respondents. There were $90.6 \%$ women, wherein $81.8 \%$ are in their 50 s and 60 s, and $68.8 \%$ are housewives. Second, the learning motivation of caregiver trainees was $64.1 \%$, mainly for employment and family support. The proportion of caregiver trainees who aim to provide for family support, self-development, and retirement rather than simple employment is steadily increasing. Third, after analyzing the personality types, the respondents are 53.1\% Kapha type. The characteristics of the Kapha type is about love and devotion, and can be said to be emotional. In particular, it shows friendly relationship characteristics to those who are obsessed with family relationships and who live around them. Kapha's personality type is characteristic of a parent or caregiver. This can be said to be the result of a well-presented Ayurvedic personality type. Fourth, it was found that there was a statistically significant relationship between learning motivation and personality type. In the case of 41 students with learning motivation and family support, 30 respondents are 73.2\% Kapha type while 11, whose learning motivation was self-developed, are 72.8\% Pitta type. The Pitta type was remarkable. They are active and have a performance-oriented trait.

The results of this study can be used as basic data for motivating caregiver trainees to learn more, and as caregiver qualification standard for career selection.

The study is limited in scope as it focused on specific location only. Further research must be conducted to supplement the conclusion of this study.

\section{References}

[1] Korea Institute for Health and Social Affairs, OECD Health Statistics, 2018, https://www.korea.kr/common/download.do?tblKey=EDN\&fileId=148655354, Aug 31 (2019)

[2] Statistics Korea, Future Population Forecast, https://kostat.go.kr/portal/korea/kor_nw/1/2/6/index.board?bmode=read\&bSeq=\&aSeq=373873\&pageNo=1\&rowNu $\mathrm{m}=10 \&$ navCount $=10 \&$ currPg $=\&$ searchInfo=\&sTarget=title\&sTxt=, March 28 (2019), pp.7-13.

[3] Korea Employment Information Service, Korean Dictionary of Occupations, https:/bartoc.org/en/node/20279, March 31 (2018)

[4] D. S. Jang, (Health and Happiness) Caregiver, USA: Bob Books, (2019) 
[5] C. M. Cho, Task Analysis of Geriatric Care Helpers Based on DACUM Method, The Korean Society of Living Environmental System, (2008), Vol.15, No.1, pp.66-75.

[6] TIMOTHY T. BALDWIN, J. KEVIN FORD, Transfer of training:, A review and directions for future research, Personnel Psychology, https://doi.org/10.1111/j.1744-6570.1988.tb00632.x

(1988), Vol.41, No.1, pp.89-103,

[7] J. H. Kim, The relationship between anneagram personality type, learning motivation, and academic achievement, Korea National University of Education, Master's Thesis, (2008)

[8] K. O. Kim, A Study on the Self leadership Mediating Effect and the Occupational Identity moderating Effect of Caregiver's Personality Type on the Relationship between the Personal Innovation Behavior and Service Quality, Seoul Venture University, Doctoral Dissertation, (2018)

[9] J. G. Lee, Job Satisfaction, Job Involvement, and Personality Types of CPA - Focusing on the Ayurveda personality type, Arts and Humanities and Social Convergence Multimedia Journal, (2019), Vol.9, No.2, pp.221-228.

[10] M. S. Cheong, A Development of the Korean Version of the constitutions in Ayurveda Questionnaire, Journal of the Korea Academia-industrial, (2016), Vol.17, No.12, pp.62-70.

[11] V. Verma, Ayurveda: A Way of Life, India: Chaukhambha Orientalia, (2000)

[12] Maya. Tiwari, Ayurveda: Secrets of Healing, India: Motilal Banarsidass Publishing House, (2003)

[13] M. S. Cheong, A study on the correlation of the method of meditation in accordance with personality type between Buddhism and Ayurveda, Korean Journal of Ayurveda, (2013), Vol.1, No.1, pp.1-22.

[14] S. D. Hwang, A Development of the Ayurveda Type Test Paper, Dongbang Culture University, Doctoral Dissertation, (2019) 